\title{
PERCEPÇÃO AMBIENTAL COMO ESTRATÉGIA DE INVESTIGAÇÃO DO AMBIENTE CONSTRUÍDO: ESTUDO DE CASO EM AMBIENTE DE TRABALHO
}

\section{ARTIGO ORIGINAL}

NIEMEYER, Michelle Caroline ${ }^{1}$

NIEMEYER, Carlos Augusto da Costa ${ }^{2}$

NIEMEYER, Michelle Caroline. NIEMEYER, Carlos Augusto da Costa. Percepção ambiental como estratégia de investigação do ambiente construído: Estudo de caso em ambiente de trabalho. Revista Científica Multidisciplinar Núcleo do Conhecimento. Ano 05, Ed. 03, Vol. 03, pp. 69-80. Março de 2020. ISSN: 2448-0959, Link de acesso: https://www.nucleodoconhecimento.com.br/psicologia/estrategia-deinvestigacao

\section{RESUMO}

O processo de planejamento do ambiente construído exige uma série de procedimentos investigativos, entre eles conhecer a percepção ambiental de seus usuários. O artigo apresenta um estudo de caso voltado à avaliação da adequabilidade de um ambiente de trabalho adotando a metodologia denominada de "atributos induzidos" também conhecida pela ferramenta "constelação de atributos", oriunda de estudos da psicologia ambiental. $O$ artigo trabalha questões comportamentais geradas a partir de aspectos físicos e sensoriais estimulados pela organização do ambiente construído e levantadas pela ferramenta investigativa. Este estudo, realizado no setor administrativo de uma empresa do ramo farmacêutico, situada na região de Campinas-SP, realizou entrevistas com funcionários visando estimular a percepção cognitiva destes com base em perguntas-chave endereçadas

\footnotetext{
${ }^{1}$ Psicóloga e Especialista em Psicologia.

${ }^{2}$ Arquiteto e Doutor em Arquitetura e Cidade pela FAU-Unicamp.
} 
pelos investigadores gerando, assim, dados que alimentam o programa computacional que identificará e qualificará atributos ambientais envolvidos na percepção. Os resultados obtidos revelam o nível de ajuste psicológico pessoaambiente, permitindo tecer informações valiosas aos investigadores para ajustamento do ambiente às necessidades de seus usuários e, consequentemente, propiciar bemestar e incremento da produtividade.

Palavras-chave: Percepção ambiental, constelação de atributos, psicologia ambiental.

\section{INTRODUÇÃO}

A arquitetura é considerada uma arte funcional ao estabelecer uma estrutura física que, quando bem resolvida, revela toda sua essência transmitindo conforto e bemestar aos usuários. Pragmaticamente, a arquitetura deve atender eficazmente aos usos ou função prevista, criando ambientações que proporcionem comodidade para o cumprimento de atividades específicas sob pena de não ser considerada uma arquitetura. A esse respeito, Zevi (1977) ilumina o fundamento clássico da boa arquitetura e seu protagonismo na criação de espaços interiores "cheio de intenções", e, assim, não se permite apreendê-lo sem envolver-se numa intensa experiência de percepção e de apropriação, visto que ela seduz nossos sentidos e nos "eleva espiritualmente". A espacialidade do corpo arquitetônico só pode ser apreendida pelo desenrolar da experiência de uso e envolvimento espacial, momento em que tomamos "posse" do lugar concretizando em toda sua plenitude a vivência da percepção que o ambiente oferece aos nossos sentidos.

Tuan (1980), ao estudar a relação entre pessoas e os lugares, perpassando pela percepção e representação espacial, descreve e nomeia essa vivência perceptiva como "sentimento de topofilia" fundamentado em elementos que despertam percepções cognitivas, sejam elas negativas ou positivas em relação ao lugar. Estudo esse que contribuiu para com o entendimento que temos hoje da dicotomia entre "lugar", entendido como recinto carregado de afetividade e "espaço", recinto indiferenciado e vago, gerando distinções opostas pela capacidade de prover experiências sensoriais distintas personificadas em sentidos de pertencimento, 
atratividade, proteção, segurança, privacidade, preservação e outros. Ettinger (1964) trabalhou essa linha de raciocínio nos ambientes de trabalho ao observar que é possível melhorar a produtividade se agregarmos melhorias ambientais aperfeiçoando a interação da pessoa com sua estação de trabalho promovendo sensações agradáveis com o lugar.

Assim, a chamada "agradabilidade" do lugar, ainda que percebida de forma inconsciente, explica, por exemplo, porque gostamos mais de um certo lugar do que de outro, instigando-nos a ajuizar como percebemos e idealizamos o mundo que habitamos e, assim por dizer, determinando nossos valores ambientais. No contexto laboral, a boa arquitetura se revela importante pela possibilidade de propiciar melhorias ambientais e construir empatias com a estação de trabalho gerando bemestar. O sentimento de agradabilidade não resolve por si problemas funcionais, mas deixa a pessoa mais confortável, estabelecendo um elo afetivo ao otimizar aspectos cognitivos, o que gera impactos positivos à produtividade do sistema de trabalho. Desde a revolução industrial, a qualidade nos ambientes de trabalho tem sido uma importante demanda, seja ela de ordem física, psicológica ou ambiental, influenciando, de forma direta ou indireta, a produtividade e a saúde ocupacional.

Nesse sentido, a preocupação com a produtividade do trabalho começou com Taylor no início do século XX e sua "Administração Científica" com o intuito de garantir o melhor custo/benefício aos sistemas produtivos. $O$ autor observou que eficiência não depende somente de incentivos e métodos, mas também de um conjunto de condições favoráveis, dentre elas a melhoria do ambiente físico. (CHIAVENATO, 2004). Hoje, a ciência do trabalho não tem dúvidas que a qualidade no ambiente de trabalho é reflexo direto de condições ambientais que são impactadas por uma multiplicidade de fatores atuantes como percepção de segurança do trabalho, adequação de carga horária, relacionamento com os colegas, e, finalmente, condições físicas como ajustes ambientais - acústicos, lumínicos, térmicos - entre outros. (SOUZA; LOURES; MARTINS, 2012).

Para Madalozzo (2016), apesar de ter havido melhorias substanciais na qualidade de vida dos trabalhadores como as conquistas organizacionais e jurídicas - sindicatos, 
leis trabalhistas, benefícios sociais e melhorias na organização do trabalho - ainda ocorre, no meio patronal, uma certa subestimação do aspecto emocional dos funcionários, como os danos causados pelo estresse no ambiente de trabalho e sintomas cognitivos pertinentes, o que pode vir a provocar desmotivação e, em consequência, perda de produtividade. De modo que, numa perspectiva sistêmica, pessoa e ambiente não são abordados separadamente e componentes físicos e psicológicos são movidos por "contextos ambientais" e "culturais", sobretudo pela ação da "memória" do usuário, evocando, então, significações que se traduzem em anseios, expectativas, julgamentos, condutas e outros mecanismos cognitivos operados como resposta sensorial dos ocupantes ao lugar que habita. (MACIEL; CAVALCANTE, 2008; DEL RIO, 1996).

Cada indivíduo responde de uma forma particular a essa relação, decorrendo ajuizamentos cognitivos que o fazem ter mais ou menos empatia com o ambiente, impressões estas que resultam no que denominamos de "percepção ambiental". Assim, o comportamento humano resulta desse processo perceptivo, isto é, dessa convivência pessoa-ambiente modulada por experiências particulares e culturais pretéritas que atuam de forma sensível no nosso modo de ver, sentir e julgar os ambientes. Neste estudo, pretende-se relatar um estudo de caso voltado à percepção ambiental de um espaço corporativo, buscando refletir acerca da adequação e qualidade dos lugares (ou ausência destes) na ótica de seus ocupantes adotando a metodologia de "atributos induzidos" também conhecida pela sua forma gráfica denominada "constelação de atributos", oriunda de estudos da psicologia ambiental. Entendemos que a qualidade ambiental está relacionada com a condição desta percepção e que se trata de uma condição perceptiva protagonista do nível de ajuste do lugar aos anseios e necessidades de seus usuários.

\section{A PERCEPÇÃo AMBIENTAL COMO ESTRATÉGIA DE COMPREENSÃO DO AMBIENTE}

Gurgel (2013) resgata a importância de um bom projeto de design de interiores como elemento "motivador de emoções nas relações humanas", e, para isso, ressalta a 
existência prévia de um briefing bem elaborado a partir de uma investigação criteriosa do perfil do usuário, dos ocupantes, de suas apreensões e das intenções de uso, o que determinará valiosas instruções ao projetista que irá facilitar a configuração final das ambientações, equipamentos, mobiliário, dimensões, estímulos visuais, conforto ambiental e demais elementos de qualificação do lugar para cumprir as funções estabelecidas. Vários conceitos emergem nesse sentido. Bernardi et al (2011) sublinha que o conceito de "acessibilidade" arquitetônica deve ser contemplado na percepção espacial do indivíduo, e, assim, experiências sensoriais são consideradas essenciais para organizar lugares e para se obter um melhor desempenho funcional e cognitivo.

Nos chamados "ambientes de proximidade", como, por exemplo, os locais de trabalho e outros, consolidou-se uma linha de abordagem projetiva chamada de "design social" que trabalha o conceito de "arquitetura da cooperação" com modelos de planejamento de viés participativo cujo projetista assume uma postura de "consultor comportamental" comprometido mais com o processo de projeto do que com o produto final (SOMMER, 1983). Participar significa tomar parte no processo de projeto, acompanhar, de forma qualificada, a construção do programa de necessidades e a definição do estético-funcional dos lugares. Distintas ferramentas investigativas para análise da percepção ambiental surgiram a partir desse propósito, de forma a ampliar o entendimento relacional pessoa-ambiente, seus anseios e demandas cognitivas para construção de lugares que proporcionem conforto e bem-estar aos seus ocupantes. (SOMMER, 1973; 2002).

Assim, construiu-se uma interdisciplinaridade e um campo novo de estudo entre arquitetura e a psicologia ambiental visando se conceber ambientes harmônicos com base no entendimento de questões de interação relacional envolvendo um coletivo de usuários e o papel dos elementos físico-cognitivos ali atuantes como mobiliário, acessibilidade, espaço dimensional, proximidade, conforto ambiental, etc que são captadas por meio de entrevistas e modelos avaliativos, apreendendo a configuração desejada ao ambiente. Hoje, sabemos que estímulos ambientais positivos ajudam a construir vínculos fortes de atratividade e pertencimento ao lugar. Nos ambientes de 
trabalho, essa noção se identifica com um ambiente harmonioso e confortável, gerador de bem-estar e propício à produtividade uma vez que operosidade é favorecida pela existência de estações de trabalho agradáveis, provocando benefícios múltiplos tanto ao trabalhador quanto a empresa, questões essas analisadas pela psicologia ambiental.

Nesse contexto, considerando tais objetivos, deve-se compreender a psicologia ambiental como uma área de estudo que afeta e age, diretamente, sob a ciência psicológica e, também, foi apropriada pela arquitetura. Devido à tais aproximações, o escopo principal é estudar, e, ainda, refletir sobre as relações que ocorrem entre os fatores ambientais e comportamentais e de que maneira isso pode impactar em nosso comportamento cotidiano em um determinado contexto (CORRAL-VERDUGO, 2005; RIVLIN, 2003). Nasceu e prosperou a partir do chamado "experimento ecológico" de Barker (1968) que estudou os efeitos ambientais no comportamento humano denominado "ambiente-comportamento", ou em sua forma inversa, denominada "comportamento-ambiente", esta quando o ambiente é lentamente afetado pelo nosso comportamento.

Assim sendo, é necessário compreender que o comportamento humano pode influenciar ou, ainda, ser influenciado pelo ambiente, podendo, dessa forma, abranger diversas escalas de abordagem como o "microambiente" (espaços domésticos), "ambientes de proximidade" (locais de trabalho e congêneres), "ambientes coletivos públicos" e até na macro escala, os grandes espaços abertos ou naturais (CAMPOSDE-CARVALHO; CAVALCANTE; NÓBREGA, 2017). Na esteira desse conhecimento, gerou-se um campo adicional de estudo denominado "ergonomia", fundamental para construção de ambientes saudáveis, e, assim, busca promover adaptações no ambiente de trabalho para proporcionar a realização de tarefas com melhor desempenho, satisfação e segurança, preservando, nesse processo, a saúde ocupacional e a produtividade no trabalho. (VILAROUCO; ANDRETO, 2008).

No processo investigativo em arquitetura e design, avaliações técnicas e avaliações comportamentais perfazem, juntas, um eficiente procedimento metodológico de controle de qualidade do ambiente construído também chamado de "Avaliação Pós 
Ocupação" (APO), com ampla utilização em diversas escalas de abordagem (ORNSTEIN, 1992). A psicologia ambiental comparece no entendimento dos aspectos psicológicos a partir do ponto de vista dos usuários, ancorada em análises ergonômicas do ambiente construído. Considerando o disposto, o estudo em tela concentra-se no entendimento dos fatores psicológicos envolvidos em um ambiente real, o escritório central de uma empresa, aqui visto como estudo de caso, buscando captar expectativas, anseios e necessidades dos usuários. A leitura e a mensuração das demandas ligadas ao campo da cognição se tornam difíceis de se mensurar sem que se faça uso de métodos apropriados como veremos.

\section{O MÉTODO E SUA APLICAÇÃO}

Os Diagramas são considerados importantes ferramentas de gestão de projeto por permitir "organizar informações e ideias para apresentação de dados quantitativos e qualitativos de forma rápida e acessível" permitindo clara visualização de resultados por mais complexo que seja o fenômeno avaliado (AMBROSE; HARRIS, 2011 apud PISSETTI; VIEIRA, 2013, p. 2). É considerada, por este aspecto, como uma importante ferramenta de gerenciamento e planejamento do design por permitir compreensão das necessidades do cliente, quaisquer que sejam as informações a serem geradas. A assimilação de uma ocorrência é mais facilmente apreendida a partir de diagramas por apresentar, geometricamente, realidades difíceis de se mensurar como, por exemplo, a imaginabilidade de um lugar.

Por este aspecto e como ponto de partida para análise e compreensão dos fatores psicológicos envolvidos nesta análise de percepção, aplicou-se o método de "atributos induzidos" ou "Constelação de Atributos" muito utilizado em pesquisas de análise ergonômica do Ambiente Construído e conhecida por sua abordagem gráfica em forma de uma constelação. Esta técnica foi idealizada, pioneiramente, por Moles (1968) e posteriormente aperfeiçoada por Ekambi-Schmidt (1974) e se destaca por permitir materializar graficamente a consciência psicológica dos usuários em relação ao espaço construído, permitindo, ainda, levantar o nível de ajuste do ambiente em relação a seus usuários. 
Ekambi-Schmidt (op. cit.), afirma que o método busca separar a imagem estereotipada da imagem subjetiva, buscando isolar e analisar variáveis psicológicas (atributos) com base em duas realidades distintas: o objeto tangível - real - e a percepção imaginária gerada pelas afinidades e condicionamentos socioculturais dos indivíduos acerca de um determinado espaço. O choque entre as duas concepções faz emergir uma série de atributos arrolados que servirão para qualificar a percepção do espaço vivido no ponto de vista se seus usuários. Duas perguntas-chave de caráter investigativo são endereçadas aos respondentes, no caso em estudo, um escritório central de uma empresa farmacêutica, situada na região e Campinas-SP. Contou-se com 08 (oito) colaboradores residentes que atuam em uma mesma e ampla sala.

A primeira pergunta endereçada sempre individualmente visou captar desejos e anseios acerca de um ambiente de trabalho hipotético que, no seu ponto de vista, causasse profunda agradabilidade: que imagens ou ideias the vêm à cabeça quando você pensa num escritório de trabalho? O objetivo foi o de acionar mecanismos culturais e de memória, ainda que condicionados por estereótipos pré-concebidos, o que exige uma filtragem feita na etapa seguinte, resultando em um rol de atributos admiráveis a um espaço hipotético. A segunda pergunta feita na sequência remete à impressão do ambiente em uso: que imagens ou ideias the vêm à cabeça quando você pensa neste ambiente de trabalho? A resposta visa captar uma opinião concreta e real de percepção ambiental naquele lugar.

As respostas são abertas e contemplou todas as respostas informadas, sempre anotadas pelo pesquisador em fichas individuais, porém não foi necessário identificar nominalmente a pessoa, o que evita receios e constrangimentos. $O$ objetivo dessas é alimentar o programa que irá gerar o mapa de percepção ambiental, identificando e quantificando atributos ligados a percepção do ambiente levantados nas duas etapas da entrevista in situ. Por fim, resultou-se na concepção de modelos gráficos para cada situação declarada. A ferramenta permite gerar, assim, uma cadeia de atributos que permite demonstrar quais são os de maior relevância obtidos nas entrevistas e classificados de acordo com a frequência de aparição nas respostas. 
Assim sendo, torna-se necessário destacar que o diagrama foi responsável por gerar "distâncias psicológicas" (as barras) cujo tamanho é calculado pelo modelo matemático (equações 1 e 2) a partir da frequência em que são citados, permitindo, dessa forma, uma visão geométrica em relação à um determinado fenômeno de caráter cognitivo. Nessa perspectivam o diagrama foi gerado e representado graficamente e, para tanto, teve como base a definição da probabilidade (Pi) de associação do atributo (i), o que acabou por gerar a "distância psicológica" (D) em "cm" que representa as conexões de cada atributo ao objeto, descritas respectivamente a seguir:

\section{Equação 1:}

Equação 2:

$$
P i=\operatorname{ni} x \frac{100}{N}
$$

$D=\frac{1}{\log P i}$

Onde:

$\mathrm{Pi}=$ probabilidade de associação do atributo $\mathrm{i}$

$\mathrm{D}=$ distância psicológica do atributo $(\mathrm{cm})$

$\mathrm{n}_{\mathrm{i}}=$ número de aparições do atributo $\mathrm{i}$

$\mathrm{N}=$ total de respostas

A ferramenta encontra-se informatizada e disponível no portal de acesso público (via Google Chrome)[3]. Duas "constelações" (real e imaginaria) foram geradas e são o centro do objeto de estudo (o escritório). Os seus atributos foram ligados por meio de linhas retas, conectadas às respostas levantadas nas entrevistas (vide quadros). Quanto mais próximas estão as conexões (em $\mathrm{cm}$ ), maior é a afinidade desse atributo com o objeto, e, em contrapartida, quanto mais distante forem as conexões (maiores 
retas), menor a relação do atributo na percepção do objeto relatado. Quando correlacionadas, os diagramas permitem mapear o fenômeno cognitivo de um coletivo frente a demandas de adequação ambiental aos usos e expectativas de agradabilidade. Cada grupo de respostas recebe um código cromático associado à sua categoria e são cores que se repetem nos gráficos.

\section{RESULTADOS E DISCUSSÕES}

Os diagramas gerados permitem a visualização do nível de ajustamento do ambiente às necessidades dos usuários cujas distâncias psicológicas (aqui observadas pelo comprimento das barras em $\mathrm{cm}$ ) refletem as demandas sensoriais levantadas. A seguir, apresentamos os quadros demonstrativos, iniciando-se pelas tabelas de atributos do ambiente imaginário e, na sequência, do ambiente real. Por fim, apresentam-se os dois diagramas em constelação correspondentes e que caracterizam a inovação deste método gráfico para o entendimento das respostas sensoriais e emocionais dos usuários em relação ao seu local de trabalho. Seguem os mapas com as devidas observações e análises pertinentes:

Tabela 1: Diagrama da Constelação de Atributos ref. Ambiente Real

\begin{tabular}{|c|c|c|c|c|}
\hline \multicolumn{5}{|c|}{$\begin{array}{l}\text { TABELA DE ATRIBUTOS ASSOCIADA AO AMBIENTE REAL } \\
\text { LOCAL DE PESQUISA: EMPRESA FARMACÊUTICA }\end{array}$} \\
\hline CATEGORIAS & ATRIBUTOS ASSOCIADOS AO AMBIENTE & QUANT. OCORRÊNCIAS & CLASSIFICAÇÃO & DIST. PSICOLÓGICA \\
\hline \multirow{4}{*}{ Conforto Ambiental } & Iluminação ruim & 6 & 2 & 0.9 \\
\hline & Acústica ruim & 5 & 3 & 0.97 \\
\hline & Barulho externo & 4 & 4 & 1.1 \\
\hline & Climatização inadequada & 2 & 6 & 1.6 \\
\hline & SUBTOTAL & 17 & & \\
\hline \multirow{3}{*}{ Ergonomia } & Cadeira desconfortável & 6 & 2 & 0.9 \\
\hline & Sala desconfortável & 4 & 4 & 1.1 \\
\hline & Mesa pequena & 2 & 6 & 1.6 \\
\hline & SUBTOTAL & 12 & & \\
\hline \multirow[t]{2}{*}{ Estética } & Visual desagradável & 1 & 7 & 3 \\
\hline & SUBTOTAL & 1 & & \\
\hline \multirow{3}{*}{ Funcionalidade } & Estação de trabalho inadequada & 7 & 1 & 0.85 \\
\hline & Ausência de área de descanso & 5 & 3 & 0.97 \\
\hline & Ausência de privacidade & 3 & 5 & 1.2 \\
\hline & SUBTOTAL & 15 & & \\
\hline \multirow[t]{2}{*}{ Manutenção } & Manutenção ruim de aparelhos & 2 & 6 & 1.6 \\
\hline & SUBTOTAL & 2 & & \\
\hline \multicolumn{2}{|l|}{ TOTAL DE RESPOSTAS } & 47 & & \\
\hline \multicolumn{2}{|c|}{ TOTAL DE ENTREVISTADOS } & 8 & & \\
\hline
\end{tabular}

Fonte: Elaborada pelos autores (2020) 


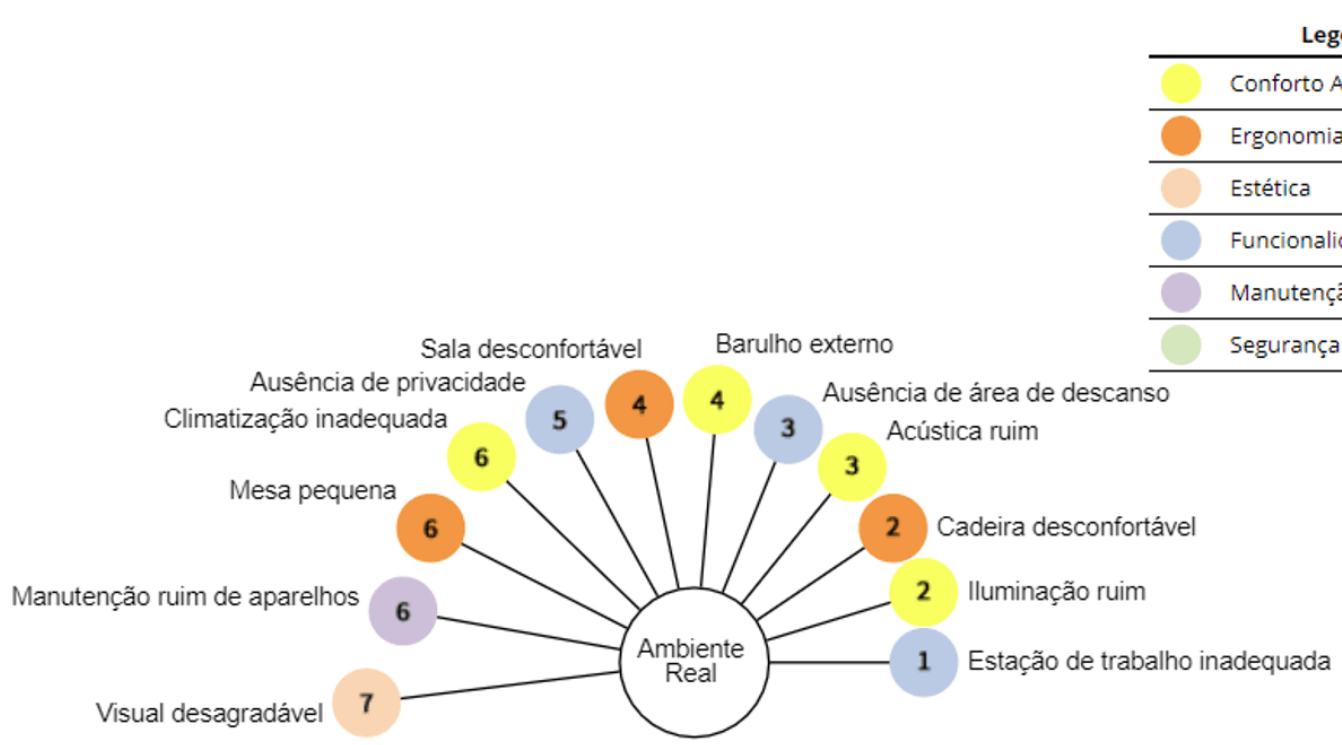

Fonte: Elaborada pelos autores (2020)

Tabela 2: Diagrama da Constelação de Atributos ref. Ambiente Imaginário

\begin{tabular}{|c|c|c|c|c|}
\hline \multicolumn{5}{|c|}{$\begin{array}{c}\text { TABELA DE ATRIBUTOS ASSOCIADA AO AMBIENTE IMAGINÁRIO } \\
\text { LOCAL DE PESQUISA: EMPRESA FARMACÊUTICA }\end{array}$} \\
\hline CATEGORIAS & ATRIBUTOS ASSOCIADOS AO AMBIENTE & QUANT. OCORRÊNCIAS & CLASSIFICAÇÃo & DIST. PSICOLÓGICA \\
\hline \multirow{3}{*}{ Conforto Ambiental } & Iluminação adequada & 6 & 2 & 0.91 \\
\hline & Climatização dos ambientes & 5 & 3 & 0.98 \\
\hline & Lugar silencioso & 5 & 3 & 0.98 \\
\hline \multicolumn{2}{|r|}{ SUBTOTAL } & 16 & & \\
\hline \multirow{2}{*}{ Ergonomia } & Ambiente confortável & 4 & 4 & 1.1 \\
\hline & Cadeiras confortáveis & 3 & 5 & 1.3 \\
\hline \multicolumn{2}{|r|}{ SUBTOTAL } & 7 & & \\
\hline \multirow{3}{*}{ Estética } & Banheiro equipado & 3 & 5 & 1.3 \\
\hline & Estação de trabalho agradável & 3 & 5 & 1.3 \\
\hline & Banheiro bonito & 1 & 6 & 3.1 \\
\hline \multicolumn{2}{|r|}{ SUBTOTAL } & 7 & & \\
\hline \multirow{4}{*}{ Funcionalidade } & Sala de descanso com copa & 8 & 1 & 0.82 \\
\hline & Estação de trabalho adequada e privativa & 6 & 2 & 0.91 \\
\hline & Mesa adequada & 1 & 6 & 3.1 \\
\hline & Sala de jogos & 1 & 6 & 3.1 \\
\hline \multicolumn{2}{|r|}{ SUBTOTAL } & 16 & & \\
\hline Manutenção & Boa manutenção geral & 1 & 6 & 3.1 \\
\hline \multicolumn{2}{|r|}{ SUBTOTAL } & 1 & & \\
\hline Segurança & Acessivel & 1 & 6 & 3.1 \\
\hline \multicolumn{2}{|r|}{ SUBTOTAL } & 1 & & \\
\hline \multicolumn{2}{|l|}{ TOTAL DE RESPOSTAS } & 48 & & \\
\hline \multicolumn{2}{|c|}{ TOTAL DE ENTREVISTADOS } & 8 & & \\
\hline
\end{tabular}

Fonte: Elaborada pelos autores (2020) 


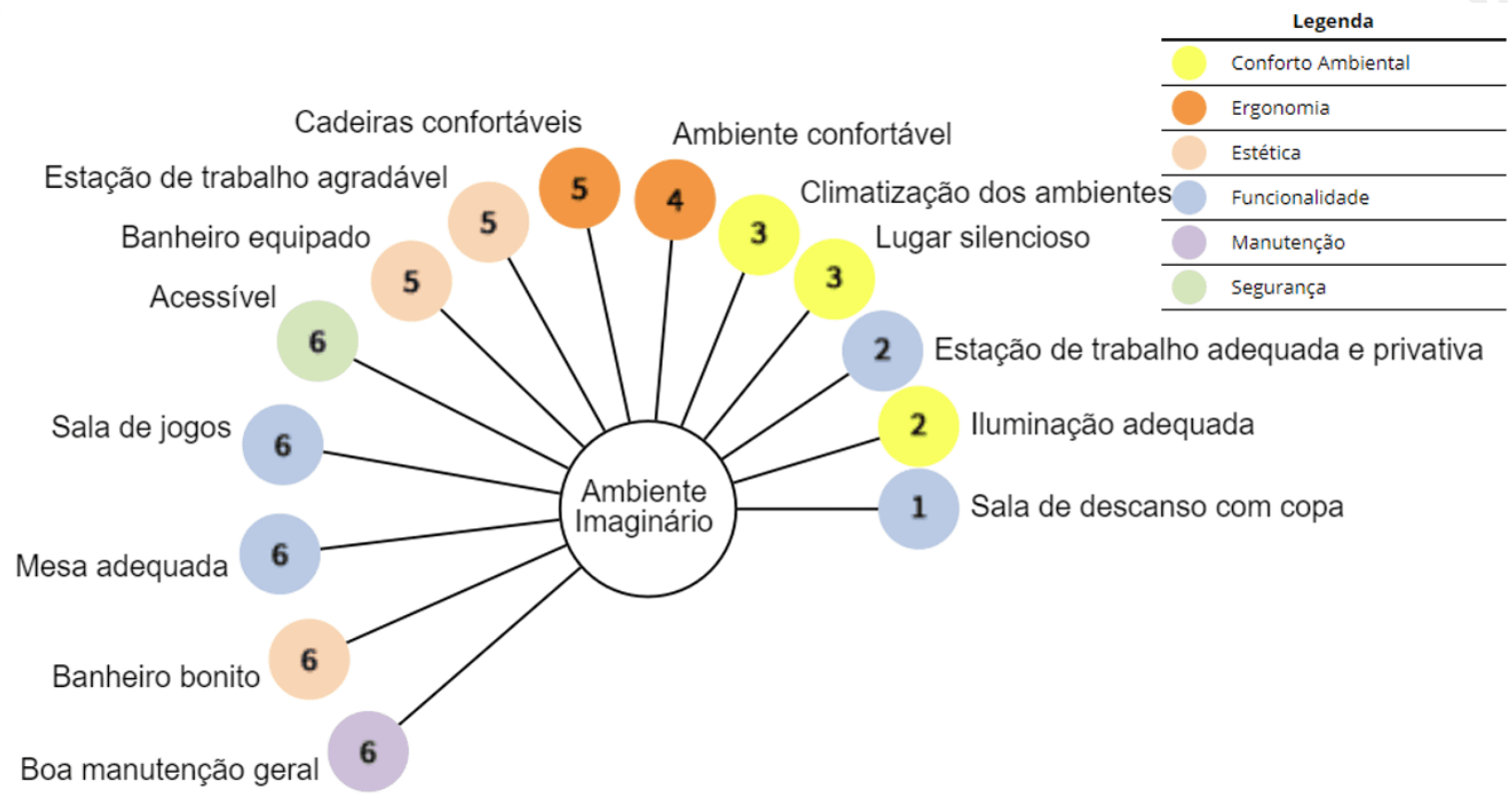

Fonte: Elaborada pelos autores (2020)

Os resultados gerados mostraram que a percepção do ambiente real é profundamente impactada por demandas ligadas ao "conforto ambiental" no recinto de trabalho. Os atributos mais levantados pelos funcionários foram pertinentes ao desempenho lumínico, térmico e acústico, o que corresponde às expectativas e anseios no ambiente imaginário onde se revelou massiva indicação por ambientes com melhor desempenho e agradabilidade nesses quesitos. Sabemos que desconforto ambiental influi nos níveis de atenção, afetando a produtividade e é responsável também pelo baixo desempenho nas atividades intelectuais. A segunda categoria mais demandada foi pertinente à "ergonomia", com forte crítica à falta de adequabilidade do mobiliário funcional, em especial cadeiras e mesas, com dimensões não ajustadas às necessidades da atividade ali desenvolvida.

Essa demanda foi responsável pela forte observação dos funcionários frente à necessidade de um mobiliário mais ajustado e ergonômico. Individualmente, quesitos ligados à "funcionalidade" angariaram forte demanda no ambiente real, em especial quanto à inadequação da estação de trabalho considerada "apertada", "desconfortável" ou "sem privacidade". No ambiente imaginário, essa demanda terá sua correspondência na percepção de maior importância às questões de qualificação 
do ambiente, aqui vistas como mais privacidade às estações de trabalho e a importância de uma "sala de descanso", referindo-se a um ambiente de permanência com copa e WC para as necessárias pausas na jornada após o almoço ou no cafezinho à tarde. Outras demandas levantadas pelos pesquisadores referem-se à estética, manutenção e segurança citadas e que podem ser traduzidas por falta de agradabilidade dos ambientes, que, se não forem consideradas, podem causar desapego, cansaço mental e desestímulo aos funcionários.

\section{CONSIDERAÇÕES FINAIS}

Um olhar atento mostra evidências de inadequação física e cognitiva na sala de trabalho, conforme expõem os diagramas desenvolvidos, explicitando que há um certo nível de desajuste no relacionamento pessoa-ambiente, o que explica a pouca empatia com as estações de trabalho, aqui entendidas como inadequações ergonômicas e funcionais. A dimensão funcional e relacional, quando bem ajustadas, é fundamental para se estabelecer um clima de atratividade com o lugar, uma vez que o espaço se relaciona intimamente com os nossos sentidos, proporcionando bemestar e, consequentemente, reforçando o sentimento de pertencimento e empatia com a empresa. Sentimentos de forte significado psicológico como empatia, segurança e pertencimento, quando não devidamente contemplados, podem gerar mal estar e impactos negativos na produtividade dos colaboradores.

O estudo de caso em tela fez emergir a importância daquilo que a boa arquitetura denomina de "ambientes restauradores" (GRESSLER, 2014; ALVES, 2011), isto é,

ambientes de "escape" que contribuem para renovar energias e reduzir a fadiga mental. Demandado nos diagramas, segundo relato dos próprios funcionários ao qual chamavam pelo sugestivo nome de "sala de descanso com copa", esses ambientes restauradores trazem benefícios físicos, mentais e sociais importantes para redução do estresse e de comportamentos antissociais, podendo ser concebidos em diferentes escalas de abordagem: no ambiente de trabalho ou na escala da edificação, perfazendo os espaços de convivência (sendo melhores os que possuem jardins). $\mathrm{Na}$ escala do bairro ou da cidade temos os jardins públicos e as praças de bairro e na 
escala da cidade temos os parques e florestas urbanas com os mesmos propósitos em escala macro.

Em todas as escalas citadas a função é a mesma: restaurar as tensões sociais e aliviar pressões cognitivas. No ambiente laboral, razão deste estudo, esses ambientes permitem uma pausa restauradora de energia, renovam a atenção $e$, consequentemente, contribuem eficazmente para com a diminuição da fadiga mental e do estresse. Atualmente, tem sido desenvolvidas novas soluções espaciais em ambientes de trabalho que priorizam as concepções programáticas para ambientes específicos próximos às estações de trabalho voltados ao "escape cognitivo", sem desmerecer outros aspectos não menos importantes ligados propriamente às estações de trabalho como as adequações ergonômicas e visuais, o que, sem dúvida, contribui para com a restauração da qualidade ambiental e do apego ao lugar. A metodologia baseada em entrevistas e montagem de diagramas demonstrou sua eficácia ao propor o levantamento gráfico sobre o fenômeno da percepção e adaptação psicológica ao lugar, demonstrando ser uma ferramenta essencial e adicional para investigar o ambiente construído.

\section{REFERÊNCIAS}

ALVES, S. Ambientes Restauradores. In: CAVALCANTE, S; ELALI, G. Temas Básicos em Psicologia Ambiental. 1ª ed. Petrópolis: Vozes, 2011.

BARKER, R. G. Ecological Psychology. Stanford: University Press, 1968.

BERNARDI, $N$. et al. $O$ desenho universal no processo de projeto. In: KOWALTOWSKI, D. et al. O processo de projeto em arquitetura: da teoria à tecnologia. São Paulo: Oficina de Textos, 2011.

CAMPOS-DE-CARVALHO, M. L; CAVALCANTE, S; nÓBREGA, L. M. A, Ambiente. In: CAVALCANTE, S; ELALI, G. Temas básicos em Psicologia Ambiental. Petrópolis: Vozes, 2017. 
CHIAVENATO, I. Introdução a Teoria Geral da Administração. Rio de Janeiro: Elsevier, 2004.

CORRAL-VERDUGO, V. Psicologia Ambiental: objeto, realidades sócio físicas e visões culturais de interações ambiente-comportamento. Psicologia USP, v. 16, n. 12, p. 71-87, 2005.

ETTINGER, K. Direção e Produtividade. Direção, Organização e Administração de Empresas. Manual de Ensino 1. 1ª ed. São Paulo: IBRASA, 1964.

EKAMBI-SCHIMIDT, J. La percepción del habitat. Barcelona: Gili, 1974.

GRESSLER, S. C. O descanso e a teoria dos ambientes restauradores. 2014. $277 \mathrm{f}$. Tese (Doutorado em Psicologia Social) - Universidade de Brasília, Brasília, 2014.

GURGEL, M. Projetando espaços. 5ª ed. São Paulo: Ed. Senac, 2013.

MACIEL, R. H; CAVALCANTE, S. Métodos de avaliação da percepção ambiental. In: GUNTHER, H; PINHEIRO, J. Q. Métodos de pesquisa nos estudos pessoaambiente. São Paulo: Casa do Psicólogo, 2008.

MADALOZZO, M. M. Preservação da Saúde e Prevenção de Acidentes de Trabalho: A Urgência da Psicologia Nesse Contexto. Estud. psicol., v. 11, n. 3, set./dez. 2016.

MOLES, A. Sociodinâmica de la Cultura. BARCELONA: Gili, 1968.

PISSETTI, R. F; VIEIRA, G. B. Processo de Design: técnicas de visualização, análise e síntese de dados. In: I Congresso de Pesquisa e Extensão da FSG, 2013.

RIVLIN, L, Olhando o passado e o futuro: revelando pressupostos sobre as interrelações pessoa-ambiente. Estudos de Psicologia, v. 8, n. 2, p. 215-220, 2003.

SOMMER, R. Social Design: Creating building with people in mind. Englewood Cliffs, NJ: Prentice-Hall, Inc, 1983.

SOMMER, R. Espaço Pessoal. São Paulo: Ed. Pedagógica e Universitária, 1973. 
SOMMER, R. O desenvolvimento e a aplicação dos conceitos de espaço pessoal. Projeto do Lugar: colaboração entre psicologia, arquitetura e urbanismo. Rio de Janeiro: Contra Capa/PROARQ, 2002.

SOUZA, A. C., LOURES, S. L. C.; MARTINS, M. F. A Qualidade de Vida no Ambiente de Trabalho Sob a Ótica dos Professores da Rede Pública. Revista Científica da FAMINAS, v.7, n. 3, p. 141-148, 2012.

TUAN, Y. F. Topofilia: um estudo da percepção, atitudes e valores do meio ambiente. São Paulo: DIFEL, 1980.

VILAROUCO, V; ANDRETO, L. Avaliando Desempenho de espaços de trabalho sob o enfoque da ergonomia do ambiente construído. Produção, v.18, n. 3, p. 523-539, set/dez. 2008.

VERGARA, S. C. Gestão de Pessoas. 16ª. ed. São Paulo. Editora Atlas, 2016.

ZEVI, B. Saber Ver a Arquitectura. 2ª . ed. Lisboa: Arcádia, 1977, 220p.

3. http://constelacao.fec.unicamp.br

Enviado: Fevereiro, 2020.

Aprovado: Março, 2020. 